\title{
THE PATTERN OF PEDIATRIC SOLID MALIGNANT TUMORS IN WESTERN KENYA, EAST AFRICA, 1979-1994: AN ANALYSIS BASED ON HISTOPATHOLOGIC STUDY
}

\author{
AHMED MWINYIMTWANA MAKATA, KAN TORIYAMA, NOAH OMOLO KAMIDIGO, \\ HIDEAKI ETO, AND HIDEYO ITAKURA \\ Department of Pathology, Institute of Tropical Medicine, Nagasaki University, Nagasaki, Japan; \\ Department of Histopathology, Rift Valley Provincial General Hospital, Nakuru, Kenya
}

\begin{abstract}
This study analyzed histopathologic specimens of 600 pediatric solid malignant tumors seen during the period 1979-1994 at the histopathology laboratories of the Rift Valley Provincial General Hospital in Nakuru, the Nyanza Provincial General Hospital in Kisumu, and the Uasin Gishu Hospital in Eldoret in western Kenya. The crude incidence rate of each malignancy per 100,000 children per year was calculated. The patterns of malignancies were examined with a focus on tumor incidence, age, sex, geographic, and ethnic distribution to relate the tumors to putative environmental and genetic causative factors. The six common tumors were Burkitt's lymphoma (33.5\%), non-Hodgkin's lymphoma (21.8\%), retinoblastoma (11.5\%), Kaposi's sarcoma (6.1\%), nephroblastoma (4.5\%), and Hodgkin's disease $(4.1 \%)$. Significantly high crude incidence rates for lymphomas and Kaposi's sarcoma showed a characteristic ethnogeographic distribution. The majority of the tumors were found concentrated around Lake Victoria and showed decreasing occurrence as one moved towards the semi-arid and highland areas. We concluded that environmental factors seem to play a major role in childhood tumors in western Kenya.
\end{abstract}

An ethnogeographic variation in the frequency of different types of tumors is mainly attributed to the interplay of varied causative factors such as exposure to ultraviolet light, ${ }^{1}$ chemical carcinogens, ${ }^{2}$ oncogenic viruses, ${ }^{3}$ genetic factors, ${ }^{4}$ and cultural practices among various populations. To carry out an epidemiologic study among the child population who have had considerably less exposure to oncogenic agents than adults would provide important information on the possible causes of the tumors. Similar epidemiologic studies done on pediatric malignant tumors in Uganda, ${ }^{5} \mathrm{Zambia}^{6}$ Sudan, ${ }^{7}$ and Nigeria $^{8}$ have provided important information on possible causes and diagnosis of childhood cancer and may be helpful in determining their etiology. However, no such study has been carried out specifically in western Kenya. Our main purpose in this study was to review histologically the pediatric solid malignant tumors in western Kenya (Figure 1) with a focus on the following specific objectives: to examine tumor incidence, age, sex, geographic, and ethnic distribution and to relate the tumors to putative environmental or genetic causative factors.

\section{MATERIALS AND METHODS}

Study area. The Republic of Kenya is situated almost exactly astride the equator. Western Kenya is divided into three provinces: Western, Nyanza, and Rift Valley (Figure 1) and has a population of $11,033,104,{ }^{9}$ about half of which are children less than 15 years old $(5,528,113) .{ }^{9}$ The climatic conditions vary from the dry semi-arid areas (500-1,500 m) in the most northern and southern parts of Rift Valley Province, through the cool and moist tropical highlands $(>2,500$ $\mathrm{m}$ ) in the center of Rift Valley Province, to the hot and moist tropical savannah around Lake Victoria in Nyanza and Western provinces $(1,100-2,500 \mathrm{~m})$. Western Kenya is inhabited by a variety of ethnic groups. The Luo and the Luhya live in Nyanza and Western Province, respectively, the Kalenjin in Rift Valley, the Turkana in northern Rift Valley, which is semi-arid like southern Rift Valley where the Masai live. The minority Kikuyu live on the periphery of Rift Valley (al- though the Kikuyu has the biggest population in Kenya, their main inhabitant area is the Central Province), and the Kisii live in the highlands of Nyanza Province. A few Asians, Arabs, Somalis, and whites are present, mostly as traders and professionals. We have chosen this area because of the following features. 1) Western Kenya provides a variety of geographic features and climatic conditions, and is composed of seven major ethnic groups (about $90 \%$ of the Western Kenya population; the remaining $10 \%$ is composed of other minority groups such as Asians, Somalis, Europeans, and Arabs). The ethnic population data are available from the census of $1989.9^{2}$ 2) The age and sex distribution of the population can be determined exactly in the provinces, as shown in the census of $1989^{9}$ (Table 1). 3) The Rift Valley Provincial General Hospital (RVPGH) in Nakuru, the Nyanza Provincial General Hospital (NPGH) in Kisumu, and the Uasin Gishu Hospital (UGH) in Eldoret receive all surgical biopsy specimens in western Kenya from the district hospitals, mission hospitals, private hospitals, private clinics, and provincial hospitals. 4) This is a rural area with little industrial pollution and the population is predominantly living in agricultural settlements; some of them are nomads with a simple life style. However, professionals, business people, office workers, and traders work and live in the urban areas.

Study population. All cancer cases less than 15 years old were considered in this study. Surgical histologic specimens were accompanied by histology request forms (HRF). Epidemiologic information was obtained from HRF on ethnicity, age, sex, area of residence, clinical history, and gross appearance of the tumor. Only specimens with this information were included in the study. A total of 676 surgical histologic specimens of pediatric solid malignant tumors were collected during a period of 16 years (1979-1994) and 76 cases were excluded because of inadequate information for analysis. The results for the remaining 600 cases are presented here. All cases of leukemia, which are not grouped in solid tumors, were also excluded in this study. Population 


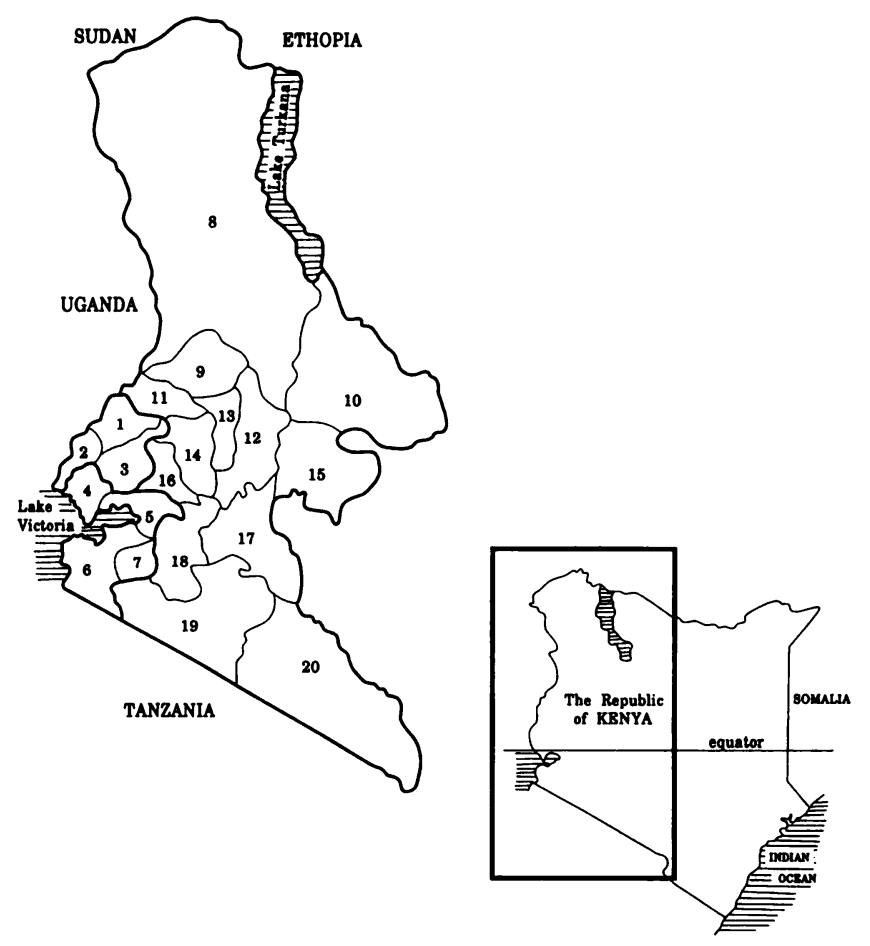

FIGURE 1. Map of the western Kenya showing districts in the three provinces. Western Province: $1=$ Bungoma; $2=$ Busia; $3=$ Kakamega; Nyanza Province: $4=$ Siaya; $5=$ Kisumu; $6=$ South Nyanza; $7=$ Kisii; Rift Valley Province: $8=$ Turkana; $9=$ West Pokot; $10=$ Samburu; $11=$ Trans Nzoia; $12=$ Baringo; $13=$ Elgeyo Marakwet; 14 = Uasin Gishu; 15 = Laikipia; 16 = Nakuru; $17=$ Kericho; $19=$ Narok; $20=$ Kajiado.

census data were obtained from the Kenya Population Census, $1989,{ }^{9}$ which is the most recent published census.

Histologic evaluation. Specimens submitted for pathologic diagnosis from various hospitals in western Kenya to the RVPGH, NPGH, and UGH laboratories were fixed in $10 \%$ formalin saline solution, embedded in paraffin, sectioned, and routinely stained with hematoxylin and eosin. Special stains also used were periodic acid-Schiff stain for glycogen, silver impregnation stain for reticulin, Van-Gieson stain for elastic fibers, and Mallory's stain for collagen fibers. The slides were examined by five pathologists (the authors of this paper) using hematoxylin and eosin stain and whenever there was a disagreement on the diagnosis, deeper cut sections and special stains were used and the slides were re-examined. The final diagnosis for all slides were made after agreement by all five pathologists.

Statistical analysis. Evaluation of the data was done using the chi-square test and the differences were considered statistically significant at a $P<0.01$ level.

\section{RESULTS}

The total number of cancer patients registered by the western Kenya laboratories during the study period of 16 years was 7,148 and of these, 676 cases were children less than 15 years old. Of these 676,600 cases were selected in this study according to our criteria. Childhood tumors therefore constituted $9.5 \%$ of all malignancies. There were 373 male
TABLE 1

Population age and sex distribution in western Kenya provinces of the population less than 15 years old (by census, 1989)

\begin{tabular}{lcccc}
\hline Province & $\begin{array}{c}\text { Age range } \\
\text { (years) }\end{array}$ & \multicolumn{1}{c}{ Male } & Female & Total \\
\hline Nyanza & $0-4$ & 328,748 & 328,243 & 656,991 \\
& $5-9$ & 293,873 & 291,272 & 585,145 \\
& $10-14$ & 258,326 & 253,763 & 512,089 \\
Western & $0-4$ & 248,600 & 249,188 & 497,788 \\
& $5-9$ & 213,167 & 214,785 & 427,952 \\
& $10-14$ & 188,483 & 189,589 & 378,072 \\
Rift Valley & $0-4$ & 473,465 & 465,453 & 938,918 \\
& $5-9$ & 422,082 & 414,434 & 836,516 \\
& $10-14$ & 351,004 & 343,638 & 694,642 \\
Total & & $2,777,748$ & $2,750,365$ & $5,528,113$ \\
\hline
\end{tabular}

cases and 227 female cases, giving a male:female ratio of 1.6:1. The crude incidence rate (CIR) of the tumors was high in children in the 5-9-year-old age group $(0.80$ per 100,000 children per year) as shown in Table 2. Table 3 shows the childhood tumor occurrence in western Kenya. Burkitt's lymphoma (BL) was the most common (33.5\%), followed by non-Hodgkin's lymphoma (NHL) $(21.8 \%)$, retinoblastoma (RB) (11.5\%), Kaposi's sarcoma (KS) (6.1\%), nephroblastoma (NB) (also called Wilm's tumor) (4.5\%), Hodgkin's disease (HD) $(4.1 \%)$, fibrosarcoma (3.2\%), squamous cell carcinoma of skin (2.6\%), osteosarcoma (2.3\%), unclassified sarcoma $(2.6 \%)$, and unclassified carcinoma (1.7\%). The percentage of the remaining tumors was $6 \%$.

The majority of specimens analyzed in this study originated from male children, except for adenocarcinoma (0.7: 1), rhabdomyosarcoma (0.5:1), and Ewing's sarcoma (0.5:1), as shown in Table 3. The age distribution observed for the six common tumors is shown in Figure 2. Retinoblastoma and NB were primarily early childhood tumors and were possibly hereditary. Kaposi's sarcoma showed an early peak between 0 and 4 years but spread into adult life, BL tended to decrease with age and, NHL and HD increased with age.

Geographic distribution. Table 4 shows the geographic distribution of six common pediatric solid malignant tumors in western Kenya. Nyanza Province, which borders Lake Victoria, and the hot and moist tropical savannah presented the highest number (281), accounting for almost half $(46.8 \%)$ of the tumors reviewed. This was supported by a CIR of 1.00, which was also the highest among the provinces. The CIR decreased progressively as one moved away from the humid and hot areas. The lymphomas and KS were the most significant malignancy $(P<0.01)$ in Nyanza Province. The lowest CIR of 0.28 was found in Rift Valley Province, which is a highland and semi-arid area. Moreover, the

TABLE 2

Age and sex distribution among 600 cases of pediatric solid malignant tumors in western Kenya (1979-1994)

\begin{tabular}{cccc}
\hline \multirow{2}{*}{$\begin{array}{c}\text { Age range } \\
\text { (years) }\end{array}$} & \multicolumn{3}{c}{ Crude incidence* (total no. of cases) } \\
\cline { 2 - 4 } & Male & Female & Total \\
\hline $0-4$ & $0.67(112)$ & $0.36(60)$ & $0.51(172)$ \\
$5-9$ & $0.94(139)$ & $0.76(99)$ & $0.80(238)$ \\
$10-14$ & $1.00(122)$ & $0.54(68)$ & $0.75(190)$ \\
Total & $0.84(373)$ & $0.52(227)$ & $0.68(600)$ \\
\hline
\end{tabular}


TABLE 3

Histologic analysis of pediatric solid malignant tumors in western Kenya $(n=600)$

\begin{tabular}{|c|c|c|c|c|c|}
\hline Histologic type & $\begin{array}{l}\text { Total no. } \\
\text { of cases }\end{array}$ & M:F & Age range* & Total \% & CIRT \\
\hline Burkitt's lymphoma & 201 & $1.8: 1$ & $2-14$ & 33.5 & 0.23 \\
\hline Non-Hodgkin's lymphoma & 131 & $1.6: 1$ & $2-14$ & 21.8 & 0.15 \\
\hline Retinoblastoma & 69 & $1.7: 1$ & $1-9$ & 11.5 & 0.08 \\
\hline Kaposi's sarcoma & 37 & $2.7: 1$ & $2-12$ & 6.1 & 0.05 \\
\hline Nephroblastoma & 27 & $1.5: 1$ & $9 m-7$ & 4.5 & 0.03 \\
\hline Hodgkin's disease & 25 & $7.3: 1$ & $4-14$ & 4.1 & 0.03 \\
\hline Fibrosarcoma & 19 & $1.4: 1$ & $1-14$ & 3.2 & 0.02 \\
\hline Squamous cell carcinoma (skin) & 16 & $1.3: 1$ & $1-14$ & 2.6 & 0.02 \\
\hline Osteosarcoma & 14 & $1.3: 1$ & 4-13 & 2.3 & 0.02 \\
\hline Rhabdomyosarcoma & 6 & $0.5: 1$ & $4 m-10$ & 1.0 & 0.01 \\
\hline Adenocarcinoma & 5 & $0.7: 1$ & $8-13$ & 0.8 & 0.01 \\
\hline Seminoma & 3 & (All males) & $7-14$ & 0.5 & 0.00 \\
\hline Neuroblastoma & 3 & (All females) & $5-7$ & 0.5 & 0.00 \\
\hline Ewing's sarcoma & 3 & $0.5: 1$ & $7-14$ & 0.5 & 0.00 \\
\hline Malignant melanoma & 2 & $1: 1$ & $10-14$ & 0.3 & 0.00 \\
\hline Hemangiopericytoma & 2 & (All females) & $5-7$ & 0.3 & 0.00 \\
\hline Angiosarcoma & 2 & $1: 1$ & $1-14$ & 0.3 & 0.00 \\
\hline Liposarcoma & 2 & (All males) & $6-8$ & 0.3 & 0.00 \\
\hline Malignant teratoma (ovary) & 2 & (All females) & $3-12$ & 0.3 & 0.00 \\
\hline Hepatoblastoma & 2 & (All males) & $8-10$ & 0.3 & 0.00 \\
\hline Synovial sarcoma & 1 & (Female) & 10 & 0.2 & 0.00 \\
\hline Transition cell carcinoma (urinary bladder) & 1 & (Female) & 6 & 0.2 & 0.00 \\
\hline Chondrosarcoma & 1 & (Male) & 12 & 0.2 & 0.00 \\
\hline Leiomyosarcoma & 1 & (Male) & 7 & 0.2 & 0.00 \\
\hline Carcinoma, unclassified & 10 & $1: 1$ & $9-14$ & 1.7 & 0.01 \\
\hline Sarcoma, unclassified & 14 & $1: 1$ & $5-13$ & 2.6 & 0.02 \\
\hline
\end{tabular}

$m=$ months; other values are years.

$+\mathrm{CIR}=$ crude incidence rate (per 100,000 children per year).

incidence of the six common pediatric solid malignant tumors showed no significant difference when compared with the same tumors in Nyanza and Western Province. Western Province showed more or less a similar pattern of solid malignant tumors compared with Nyanza Province.

Ethnic distribution. Table 5 shows the overall aggregate

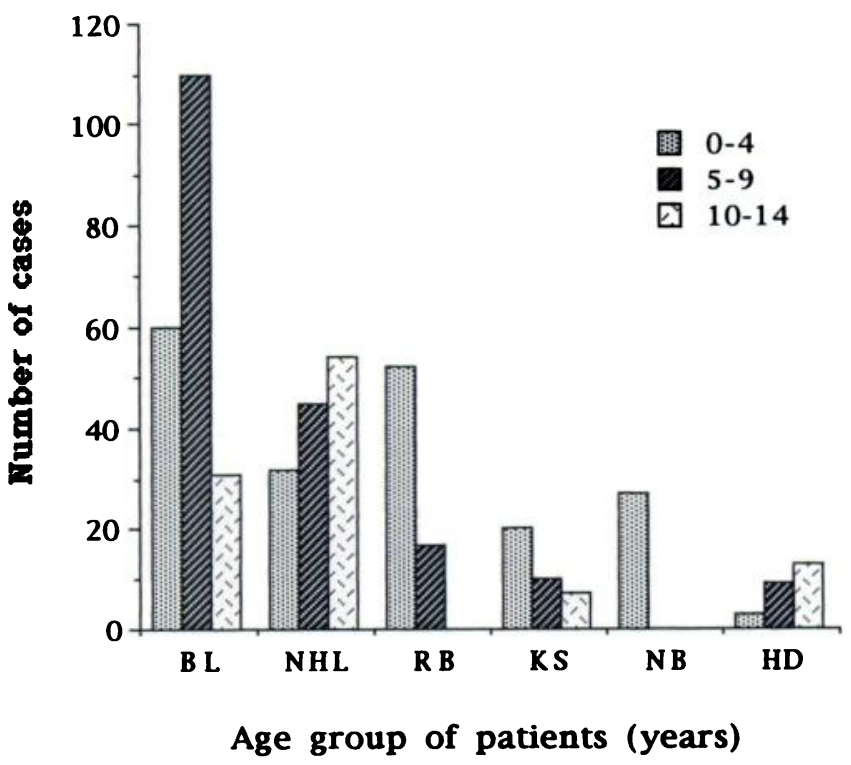

Figure 2. Age distribution of six common tumors. BL $=$ Burkitt's lymphoma; NHL = non-Hodgkin's lymphoma; $\mathbf{R B}=$ retinoblastoma; $\mathrm{KS}=$ Kaposi's sarcoma; $\mathrm{NB}=$ nephroblastoma; $\mathrm{HD}=$ Hodgkin's disease. of tumor cases per ethnic group. The ethnic population of children less than 15 years of age was estimated to be $50 \%$ of the tribe population of western Kenya, as seen in the census of 1989.9 (The child population of western Kenyan is about $50 \%$ of the total population. ${ }^{9}$ ) For the Luo, BL showed the highest CIR of 0.78 followed by NHL (0.38) and KS (0.15). Statistically, these three tumors were more significant $(P<0.01)$ in this tribe. The CIR of BL and NHL showed a similar pattern of dominance among the Luhya and Kalenjin, but KS in Luhya showed a CIR of 0.04 and was significant in the other tribes except in the Luos. The majority of cases of RB were found in the Luhya, and the rest of the tumors showed a more or less even occurrence with no significant differences in the tribes. Nephroblastoma was rare but almost evenly distributed among the major tribes except in the Luo, where only two cases were record-

TABLE 4

Geographic distribution of the six common pediatric solid malignant tumors in western Kenya (1979-1994)

\begin{tabular}{llll}
\hline & \multicolumn{3}{c}{ Crude incidence* (total cases) } \\
\cline { 2 - 4 } \multicolumn{1}{c}{ Tumor } & \multicolumn{1}{c}{$\begin{array}{c}\text { Nyanza } \\
\text { Province }\end{array}$} & $\begin{array}{c}\text { Western } \\
\text { Province }\end{array}$ & $\begin{array}{c}\text { Rift Valley } \\
\text { Province }\end{array}$ \\
\hline Burkitt's lymphoma & $0.52(145)$ & $0.14(30)$ & $0.07(26)$ \\
Non-Hodgkin's lymphoma & $0.27(76)$ & $0.07(15)$ & $0.10(40)$ \\
Retinoblastoma & $0.07(20)$ & $0.12(24)$ & $0.06(25)$ \\
Kaposi's sarcoma & $0.09(25)$ & $0.05(10)$ & $0.01(2)$ \\
Nephroblastoma & $0.01(4)$ & $0.05(11)$ & $0.03(12)$ \\
Hodgkin's disease & $0.04(11)$ & $0.04(8)$ & $0.02(6)$ \\
Total & $1.00(281)$ & $0.47(98)$ & $0.28(111)$ \\
\hline
\end{tabular}

* Per 100,000 children per year. 
TABLE 5

Ethnic distribution of the six common solid malignant tumors in western Kenya (1979-1994)

\begin{tabular}{llccccc}
\hline & \multicolumn{5}{c}{ Crude incidence* (total cases) } \\
\cline { 2 - 6 } Ethnic groups & BL & NHL & RB & KS & NB \\
\hline Luo & $0.78(142)$ & $0.38(69)$ & $0.05(10)$ & $0.15(27)$ & $0.01(2)$ & $0.06(11)$ \\
Luhya & $0.14(30)$ & $0.09(20)$ & $0.12(26)$ & $0.04(9)$ & $0.04(10)$ & $0.04(9)$ \\
Kalenjin & $0.10(20)$ & $0.09(17)$ & $0.06(12)$ & N/C & $0.03(6)$ & $0.03(5)$ \\
Kikuyu & $0.01(1)$ & $0.16(13)$ & $0.08(10)$ & N/C & $0.03(6)$ & N/C \\
Kisii & $0.07(7)$ & $0.07(7)$ & $0.07(7)$ & $0.01(1)$ & N/C & N/C \\
Turkana & $0.05(1)$ & N/C & $0.05(1)$ & N/C & $0.05(1)$ & N/C \\
Kuria & N/C & $0.12(1)$ & N/C & N/C & N/C \\
Masai & N/C & $0.04(1)$ & N/C & N/C & N/C & N/C \\
Teso & N/C & N/C & $0.07(1)$ & N/C & N/cC \\
\hline
\end{tabular}

- Per 100,000 children per year. BL = Burkitt's lymphoma; NHL = non-Hodgkin's lymphoma; RB = retinoblastoma; KS = Kaposi's sarcoma; NB = nephroblastoma; HD = Hodgkin's disease; $\mathrm{N} / \mathrm{C}=$ no case.

ed. Tumors in the rest of the tribe were too few to warrant any evaluation.

\section{DISCUSSION}

There are many difficulties in the accurate enumeration of cancer cases from a defined population in the developing countries. However, data used in this study are hospitalbased and are as unbiased as possible. The incidence for the respective age range, peak age, and sex found in western Kenya for six common pediatric solid malignant tumors concur with those previously documented in developed countries. ${ }^{10.11}$ The order of the frequency for each type of tumor is quite different from what is observed in the temperate region and conforms more to the tropical African pattern of childhood tumors. The pattern of childhood malignancies in western Kenya is essentially similar with that in neighboring countries in general, ${ }^{6-8}$ with the exception of Zimbabwe ${ }^{12}$ and Sudan, 5 which have a high incidence of NB and RB, respectively, and a low incidence of BL. In this study, BL was the most common tumor, RB was the third most common, and NB was the fifth most common in western Kenya.

Ever since Burkitt ${ }^{13}$ published his original paper on a sarcoma affecting the jaws of African children, the tumor, which was later reclassified as a B cell lymphoma, ${ }^{14}$ a number of subsequent studies have shown a direct association between BL and geographic location. In this aspect, a causative relationship has been drawn between the lymphoma and certain environmental factors defined by geographic location, such as malaria in the rainy humid zones of Africa. ${ }^{15.16}$ Our results have described a similar relationship of BL with geographic distribution. Besides BL, we have reviewed in detail five additional different histologic types of pediatric solid malignant tumors in the BL-endemic areas. Many of tumors showed a high concentration around the humid and hot shores of Lake Victoria in Nyanza Province, where malaria is hyperendemic, ${ }^{17}$ and other parasitic infections are also present. Non-Hodgkin's lymphoma, KS, and HD also showed a high incidence in Nyanza Province. Similar results for $\mathrm{BL}$ and $\mathrm{KS}$ distribution were found around the Lake Victoria in the neighboring country of Tanzania. ${ }^{18}$

The majority of the western Kenyan population are rural dwellers leading a peasant or nomadic life style. It is well known that communities of low socioeconomic status tend to carry a higher disease burden than the well to-do com- munities who have access to treatment and good nutrition. There is a possibility of widespread immunosuppression that results from chronic infections in the population or some oncogenic agents in the area or both. Chronic infection results in immunodeficiency that may be conducive to the development of neoplasm. On the other hand, the Rift Valley Province, which has semi-arid and highland areas, showed low tumor incidence probably because of low levels of infections, such as malaria and other chronic infections. Currently, Epstein-Barr virus (EBV) has been implicated as an oncogenic agent, not only for $\mathrm{BL}^{19}$ but also for $\mathrm{HD},{ }^{20}$ that takes advantage of the suppressed immune system. One wonders if the ubiquitous EBV alone could play a causative role in BL or if there is another agent or virus associated with malaria having a similar role as EBV.

It is interesting to note that BL, NHL, and KS had a high incidence in the Luos in Nyanza Province in western Kenya. Previous studies on ethnic distribution have shown similar findings with KS. ${ }^{21,22}$ These observations somehow place the Luos in a special category. Although the reason for these variations is not understood, environmental factors seem to play a role in the etiology. In Tanzania, the Bende and Shirazi tribes had the highest tribal incidence of KS. ${ }^{23}$ Therefore, further studies are also needed along the lines of the ethnic groups and the tumors. Two other tumors, RB, which was observed in the majority of cases in the Luhya children and did not show any influence by geographic factors (the cases were equally distributed in the provinces) and NB, did not show any significant geographic or ethnic distribution. Our observation shows that there is a decrease in lymphoreticular malignancies and KS incidence between the hot and humid areas around Lake Victoria and the semi-arid or tropical highlands in the Rift Valley Province. This points out a definite conclusion that environmental factors seem to play a major role in the etiology of childhood malignancy in western Kenya. Also, because children have low exposure to carcinogenic predisposing factors, they become a suitable model population for focusing on the environmental factors that may be the cause of malignancy in this area, especially for lymphoreticular tumors and KS.

Acknowledgments: We thank all members of Nakuru Provincial Hospital, Kisumu Provincial Hospital, and Uasin Gishu Hospital in Eldoret (Department of Histopathology) for help in collecting the request forms, slides, and blocks. 
Financial support: This work was supported by grants-in-aid from the Ministry of Education, Science, Sports and Culture of Japan.

Authors' addresses: Ahmed Mwinyimtwana Makata, Kan Toriyama, Hideaki Eto, and Hideyo Itakura, Department of Pathology, Institute of Tropical Medicine, Nagasaki University, 1-12-4 Sakamoto, Nagasaki 852, Japan. Noah Omolo Kamidigo, Department of Histopathology, Rift Valley Provincial General Hospital, PO Box 71, Nakuru, Kenya.

Reprint requests: Ahmed Makata Mwinyimtwana, Department of Pathology, Institute of Tropical Medicine, Nagasaki University, 112-4 Sakamoto, Nagasaki 852, Japan.

\section{REFERENCES}

1. Miller RW, Boice JD Jr, 1986. Radiagenic cancer after prenatal or childhood exposure. Upon AC, Burns FJ, Shore RE, eds Radiation Carcinogeneses. New York, Elsevier, 379-386.

2. IARC monographs on the evaluation of carcinogenic risks of chemicals to humans, October 1982. Chemical, industrial process and industries associated with cancer in humans. IARC Monograph (suppl 4): 1416.

3. De-The G, 1985. Role of the Epstein-Barr virus in human diseases. Klein C, ed. Viral Oncology. New York: Raven Press, 761-797.

4. Miller RW, 1986. Gene, syndrome and cancer. Pediatr Rev 8: 153-158.

5. Davies JNP, 1973. A survey of Uganda 1964-1968. Templeton AC, ed. Tumour in a Tropical Country. Recent Results in Cancer Control. New York: Springer-Verlag, 306-321.

6. Patil FS, Elem B, Gwavava NJP, Urban MI, 1992. The pattern of paediatric malignancy in Zambia (1980-1989): a hospitalbased histopathological study. J Trop Med Hyg 65: 124-127.

7. Hussain MAM, Ahass FEM, Ahmed HM, 1988. Malignant disease in Sudanese children. E Afri Med J 65: 507-513.

8. William $O, 1975$. Tumour of childhood in Ibadan, Nigeria Cancer 36: 370-378.
9. Central Bureau of Statistical, 1989. Kenya population census.

10. Birch JM, Marsden HB, Swindell R, 1980. Incidence of malignant disease in childhood: a 24-year review of the Manchester children's tumour registry data. Br J Cancer 42: 215-223.

11. Roush SW, Krischer JP, Pollock NC, Cox MW, Pollock BH, Bayer J, 1992. The incidence of pediatric cancer in Florida, 1981-1986. Cancer 67: 2212-2219.

12. Nkanze NK, 1989. Paediatric solid malignant tumour in Zimbwabwe. Cent Afr J Med 35: 497-500.

13. Burkitt DP, $1958 / 1959$. A sarcoma involving the jaw in African children. Br J Surg 46: 218-223.

14. Fialkow PJ, Klein G, Gartler SM, 1970. Clonal origin for individual Burkitt tumors. Lancet $i$ : 384-386.

15. Hurt MSR, Burkitt DP, 1965. Geographical distribution of cancer in East Africa. Br Med J ii: 719-722.

16. Biggar RJ, Nkrumah FK, 1979. Burkitt's lymphoma in Ghana: urban rural distribution, time-space clustering and seasonality. Int $J$ Cancer 23: 330-336.

17. Kamunvi F, Njino MJ, 1985. Epidemiology of jaw tumours in Nyanza province with special reference to Burkitt's lymphoma: report of preliminary findings at the Nyanza General Hospiatl. E Afr Med J 62: 122-128.

18. George A, Alexander MD, 1983. Geographical aspects of cancer in Tanzania. J Natl Med Assoc 75: 797-804.

19. Hirshant Y, Cohen MH, Steven DA, 1973. Epstein-Barr virus antibodies in American and African Burkitt's lymphoma. Lancet ii: 114-116.

20. Lange B, Arbeter A, Hewetson J, Henle W, 1978. Longitudinal study of Epstein-Barr virus antibody titer and excretion in pediatric patients with Hodgkin's disease. Int J Cancer 22: 521-527.

21. Toriyama K, Uzuta F, Itakura H, Kamidigo NO, 1987. Geographical study on endemic Kaposi's sarcoma in Western Kenya. Trop Med 29: 87-100.

22. Toriyama K, Uzuta F, Itakura H, Kamidigo NO, 1987. Kaposi's sarcoma of the lymph node(s) in western Kenya. Trop Med 29: $101-106$.

23. Schmid H, 1976. Kaposi's sarcoma in Tanzania: a statistical study of 220 cases. Trop Geogr Med 25: 266-276. 